\title{
ANÁLISE ESPAÇO TEMPORAL DO CRESCIMENTO DA MANCHA URBANA DO BAIRRO COLINA DE LARANJEIRAS - SERRA/ES A PARTIR DA UTILIZAÇÃO DE IMAGENS GOOGLE EARTH
}

\author{
Rubyana dos Santos Vieira ${ }^{(a)}$, Jordano Francesco Gagno de Brito ${ }^{(b)}$, Eliana Cassia Rocon ${ }^{(c)}$, \\ Daiane Entringer Modesto ${ }^{(d)}$ \\ (a) Universidade Federal do Espírito Santo - UFES - ${ }^{1}$ rubyana.vieira@ gmail.com; \\ (b)Universidade Federal do Espírito Santo - UFES - ${ }^{2}$ jordanofrancesco@gmail.com; \\ (c)Universidade Federal do Espírito Santo - UFES - ${ }^{3}$ elianarocon@gmail.com; \\ (d)Universidade Federal do Espírito Santo - UFES - ${ }^{4}$ dai_em@ @otmail.com.
}

\section{Eixo: GEOTECNOLOGIAS E MODELAGEM ESPACIAL EM GEOGRAFIA FÍSICA}

\begin{abstract}
Resumo
O município de Serra, em meados do ano de 2000 obteve uma nova função, considerado como periferia, o mesmo acolhia a população de baixa renda além de trabalhadores de classe média baixa, vinculados a grandes empresas, com isso, município passou de lugar da indústria no contexto da Grande Vitória a lugar de moradia destes trabalhadores. Diante disto, o objetivo desta pesquisa consistiu em realizar um mapeamento espaço temporal da ocupação urbana que aconteceu no bairro Colina de Laranjeiras, no município de Serra - ES. Desde o início de sua construção até os dias atuais, o bairro passou por um período de transformações decorrente do processo de industrialização do município, tanto em sua extensão territorial, como o seu crescimento populacional. Foram analisadas imagens obtidas por meio do Google Earth (imagens de arquivo DigitalGlobe), no período de 2003 e 2013 e a elas foram aplicadas técnicas do Sensoriamento Remoto.
\end{abstract}

Palavras-chave: Sensoriamento Remoto, urbanização, Sistemas de Informações Geográficas.

\section{Introdução}

O processo de urbanização no Brasil ocorreu com maior intensidade a partir da década de 1970, quando houve fluxo considerável de migrações de pessoas do campo para a cidade. Esse fato implicou na necessidade de expansão de áreas para uma melhor acomodação de moradias, comércio e indústrias. Compreende-se portando, que o desenvolvimento econômico e tecnológico de uma região tende a atrair o crescimento populacional, que exerce uma pressão nas cidades.

Assim como em outras localidades, o município de Serra que pertence a RMGV - Região Metropolitana da Grande Vitória/ES, também atraiu um grande contingente populacional que permanece alterando a configuração de seu território. Sua posição geográfica e suas facilidades logísticas fizeram com que se tornasse um dos mais significativos pólos de desenvolvimento urbano e 
industrial do Estado, e uma das cidades mais prósperas do Brasil. Pode-se perceber isso na afirmação de Gonçalves (2009, p. 69 e 70),

Historicamente, a dinâmica urbana de Serra esteve associada à expansão periférica da metrópole da Grande Vitória, com a consolidação do processo de industrialização a partir da segunda metade da década de 1970. Assim, parte do território do município, de um lado, foi utilizada como suporte para a atividade industrial e, por outro, como lócus para a reprodução da população com menos rendimento, que chegava aos milhares à Grande Vitória nos anos 1970 e 1980.

Paralelo ao desenvolvimento urbano do município surgiram interesses que alavancaram o processo das edificações em suas várias formas. Concomitante a isto, temos a especulação imobiliária, um processo que nas últimas décadas está direcionado a construções de grande porte como, por exemplo, os condomínios fechados em regiões onde predominam localidades próximas consideradas de periferia, conforme Corrêa (1999, p.85),

[...] o processo de segregação socioespacial, quando as camadas de maior renda passam a buscar melhores condições de moradia, conforto e comodidade. Isso vem acirrar as desigualdades da ocupação dos espaços e a auto-segregação dos grupos menos abastados na reprodução da moradia, empurrados cada vez mais para áreas periféricas, com limitações da estrutura urbana.

O presente trabalho tem como objetivo principal analisar a evolução espaço temporal da ocupação urbana no bairro Colina de Laranjeiras (figura 1), localizado no município de Serra/ES, utilizando-se das técnicas de Sensoriamento Remoto e Sistemas de Informações Geográficas.

\section{2. Área de Estudo}

A área de estudo (Figura 1) compreende o bairro Colina de Laranjeiras, localizado no município de Serra e tem como área limite a rodovia Norte Sul uma das principais rodovias do Município de Serra, os bairros Taquara I e II e Chicocity ao Sul. 


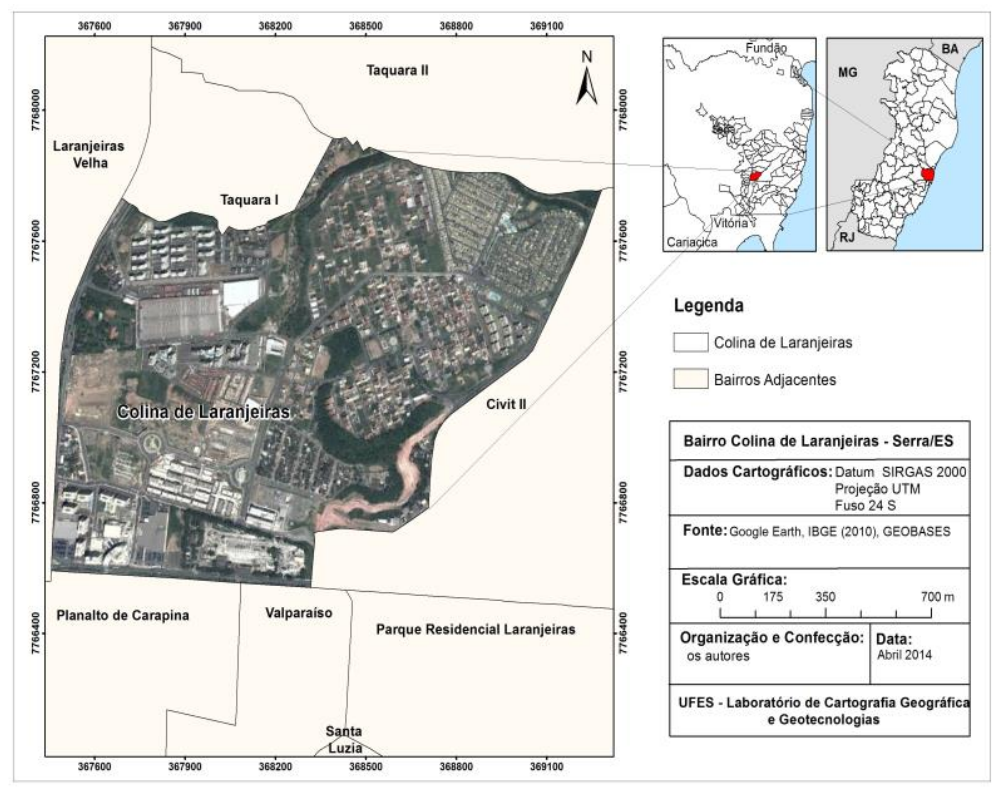

Figura 1. Localização do bairro Colina de Laranjeiras - Serra/ES.

O loteamento Colina de Laranjeiras, que antes pertencia ao bairro Taquara I distrito de Carapina, conta com uma área total de 1.642.128,63 $\mathrm{m}^{2}$. A área é composta basicamente por moradias que em sua maioria são representadas por condomínio fechados de alto padrão, além de algumas empresas do segmento logístico.

\section{Metodologia de trabalho}

Para realização deste trabalho, o mesmo foi dividido em duas principais etapas, partindo da aquisição de referencial bibliográfico referente a problemática estudada, como: livros, periódicos, dissertações e teses. A segunda etapa iniciou-se com a aquisição dos seguintes Planos de Informações: limite municipal (IDAF, 2014); limite de bairros (IJSN, 2014); limite de estados (IBGE, 2014); ortofotomosaico (IEMA 2007/2008); imagens de alta resolução espacial coletadas no programa Google Earth, com datas de passagem em 06/11/2003 e 26/12/2013.

Iniciou-se com o pré-processamento das imagens do programa Google Earth e Ortofotomosaico IEMA, e com as imagens selecionadas deu-se início ao processo de georreferenciamento, para o mesmo foram utilizados entre 6 e 10 pontos, foi utilizada a projeção cartográfica (UTM, SIGARSS 2000, fuso 24S).

Após o processo de georreferenciamento das imagens foi realizada a etapa de extração de informações através da classificação supervisionada e interpretação visual das imagens de satélite. Para a classificação supervisionada foram estabelecidas 03 classes (urbano, vegetação e descampado). 
Anterior ao início do processo da classificação supervisionada, foram criados arquivos no tipo vetores no formato de polígonos para cada imagem referente aos anos estudados (2003 e 2013), o objetivo destes vetores, foi editar amostras de cada tipo de classe estabelecida, com intuito de coletar o maior número possível das mesmas. Com isso, foi possível uma melhor análise e consequentemente um melhor resultado, pois algumas informações geradas não condiziam com a real situação do local, necessitando de correção manual. Após o processo final de interpretação das imagens, realizou um Clip do plano de informação de Bairros (IJSN, 2014) com o plano de informação que continha as classes de uso do solo, gerando assim um recorte referente ao bairro estudado, Colina de Laranjeiras.

Concluída a etapa no software ArcGis 10.1, os resultados alcançados foram trabalhados na ferramenta Excel, originando gráficos e tabelas que possibilitaram uma melhor análise.

\section{Resultados e Discussão}

Com a elaboração de mapas, foi possível delimitar o crescimento da mancha urbana no bairro Colina de Laranjeiras/Serra para os anos de 2003 e 2013, e a localização das áreas de concentração, facilitando a visualização do processo de desenvolvimento urbano. Nas figuras resultantes (2 e 3), as cores dos polígonos correspondem às classes estabelecidas (descampado, urbano e vegetação).

Com o intuito de detalhar e refinar os resultados obtidos foram calculados os percentuais para cada classe (descampado, urbano e vegetação) dos anos analisados, onde foram encontrados para o ano de 2003 (figura 2), os seguintes valores 37\% descampado, 32\% urbano e 31\% vegetação.

Diante destes valores observou-se que a área total com cerca de $1.642 .128,63 \mathrm{~m}^{2}$, se apresentava com uma proporção semelhante para todas as classes estabelecidas. Sendo que a área correspondente ao uso urbano, era composta por empresas de diversos segmentos.

Em um período de 10 anos, estes valores tiveram uma mudança expressiva, conforme encontrado nos percentuais para o ano de 2013 (figura 2), a classe urbana saiu do percentual de 32\%, o que correspondia a $519.793,90 \mathrm{~m}^{2}$ da área total e passou a ser de $67 \%$, correspondendo a $1.096 .201,27 \mathrm{~m}^{2}$ da área total. Com isso, é correto afirmar que a expansão urbana presente neste bairro, foi intensa, levando um curto período de tempo, o que pode se relacionar ao de desenvolvimento econômico, presenciado pelo município de Serra neste período. 


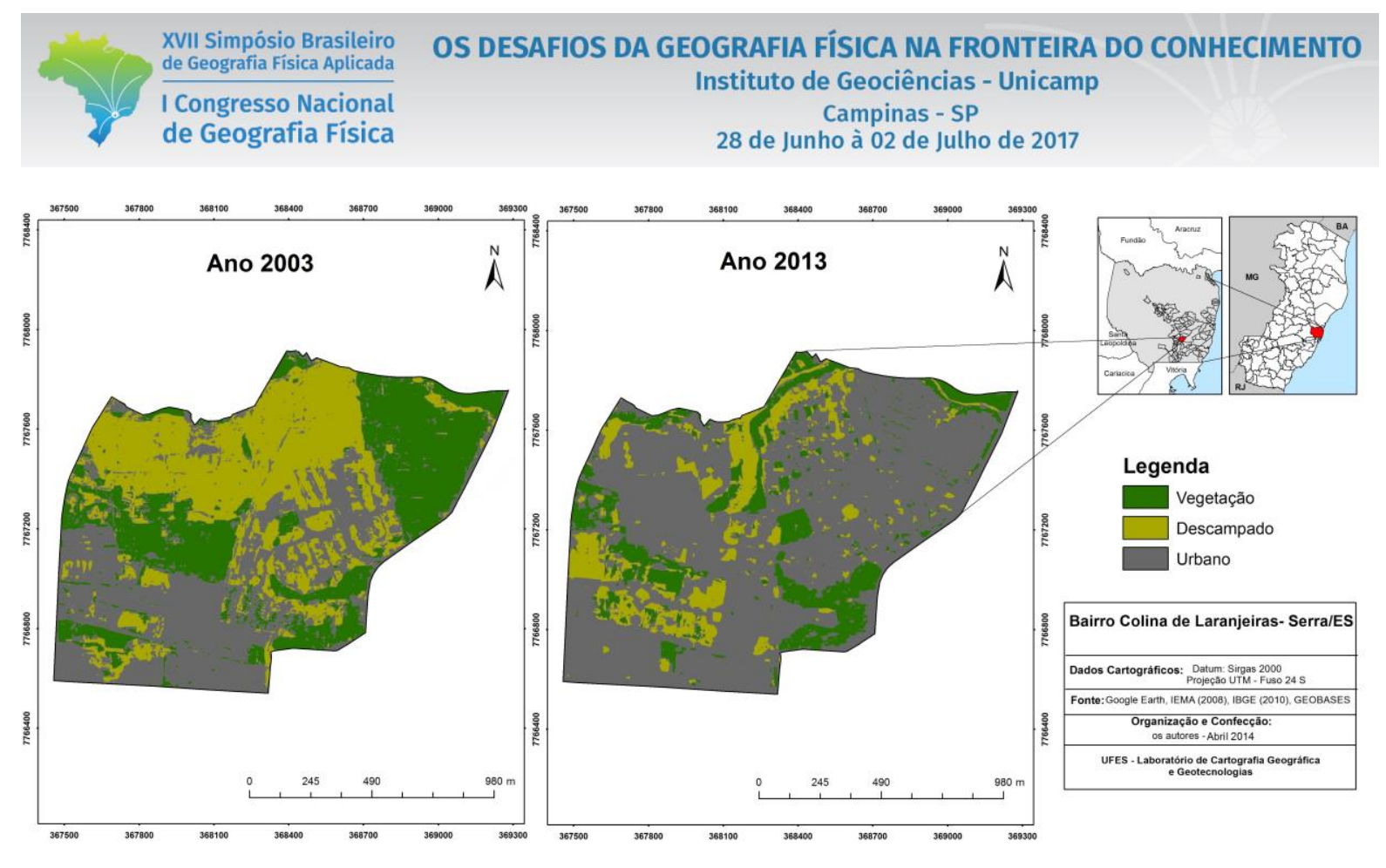

Figura 2. Uso e cobertura da terra anos 2003 e 2013.

Por meio das análises obtidas, verificou-se que as mudanças, principalmente as econômicas ocorridas no município de Serra influenciaram o crescimento da mancha urbana no bairro Colina de Laranjeiras. Carlos (2007, p.35) em seus estudos nos traz essa relação,

[...] as transformações dos bairros são bastante significativas, uma vez que adensam-se, ganham novas atividades e novos moradores, mudando de perfil em poucos anos, às vezes, meses. Os contrastes, que não cessam de se aprofundar, revelam se, com toda sua força no plano da habitação.

De fato, a formação social é uma particularidade espaço-temporal de um determinado modo de produção, quer dizer, é uma combinação particular e relacional de uma ordem temporal e de uma ordem espacial de um dado modo de produção dominante (BESSA, 2010).

\section{Conclusão}

O crescimento urbano é um processo presente nas grandes cidades, sendo assim, buscou-se compreender as transformações ambientais e sociais geradas pelo mesmo no local de estudo. Considerando que o levantamento do uso e cobertura da terra atualmente é de extrema importância para que se acompanhe e entenda de que forma está sendo utilizada a mesma, além de compreender como se apresenta a nova configuração dos padrões de organização do espaço territorial. Neste campo de estudo, muitas são as ferramentas de geotecnologias que auxiliam na execução deste procedimento, portanto, este estudo utilizou-se do desempenho de softwares como ArcGis $10.1 \mathrm{e}$ Google Earth, visando conferir um detalhamento mais minucioso a temática proposta. 
Estas tecnologias possibilitam estudos relacionados às mudanças ocorridas no espaço em que se vive e proporcionam uma visão multitemporal das áreas estudadas, destacando as transformações ocorridas em determinados períodos, tornando-se fortes mecanismos no acompanhamento de desmatamentos, queimadas, expansão urbana, ou outras alterações do uso e da ocupação da terra ocasionadas pelo homem.

Por meio das análises obtidas com este estudo, verificou-se que as mudanças ocorridas no município de Serra influenciaram o crescimento da mancha urbana no bairro Colina de Laranjeiras, gerando uma competição entre os diferentes grupos da população, onde a cada dia o uso da terra torna-se mais que uma questão de uso e ocupação e passa a adquirir valores que estão diretamente relacionados a seus agentes, que acabam por influenciar diretamente na transformação e reprodução do espaço social.

\section{Referências}

BESSA, Kelly. Diferenciação espacial como elemento próprio à natureza da geografia. Mercator (Fortaleza. Online), v. 9, p. 43-56, 2010. Disponível em: $<$ http://www.mercator.ufc.br/index. php/mercator/article/viewFile/394/308>. Acesso em: <abril 2014>.

CARLOS, Ana Fani Alessandri. O Espaço Urbano: Novos Escritos sobre a Cidade. São Paulo: Labur Edições, 2007.

CAMPOS FILHO, Candido Malta. Cidades brasileiras: seu controle ou o caos. $4^{\text {a }}$ ed. São Paulo: Studio Nobel, 2001.

CORRÊA, Roberto Lobato. O espaço urbano. 4. ed. São Paulo: Ática, 1999.

GONÇALVES, Thalismar Matias. A dinâmica do espaço urbano: um estudo sobre o bairro Parque Residencial Laranjeiras, Serra - ES. 2007. Monografia - graduação em bacharel do curso de Geografia, Universidade Federal do Espírito Santo, Vitória, 2007. 